\title{
MicroRNA-141 Represses HBV Replication by Targeting PPARA
}

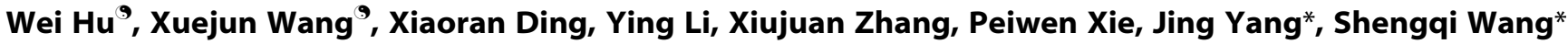

Beijing Institute of Radiation Medicine, Beijing, People's Republic of China

\begin{abstract}
MicroRNAs (miRNAs) are small non-coding RNAs that regulate gene expression primarily at the post-transcriptional level and play critical roles in a variety of physiological and pathological processes. In this report, miR-141 was identified to repress HBV expression by screening a small miRNA expressing library and synthetic miR-141 mimics could also significantly suppress HBV expression and replication in HepG2 cells. Bioinformatic analysis and experiment assays indicate that peroxisome proliferator-activated receptor alpha (PPARA) was the target of hsa-miR-141 during this process. Furthermore, knockdown of PPARA by small interfering RNA (siRNA) inhibited HBV replication similar to levels observed for miR-141. Promoter functional analysis indicated that repression of HBV replication by miR-141 mimics or siRNA was mediated by interfering with the HBV promoter functions, consistent with previous studies demonstrating that PPARA regulated HBV gene expression through interactions with HBV promoter regulatory elements. Our results suggest that miR-141 suppressed HBV replication by reducing HBV promoter activities by down-regulating PPARA. This study provides new insights into the molecular mechanisms associated with HBV-host interactions. Furthermore, this information may facilitate the development of novel anti-HBV therapeutic strategies.
\end{abstract}

Citation: Hu W, Wang X, Ding X, Li Y, Zhang X, et al. (2012) MicroRNA-141 Represses HBV Replication by Targeting PPARA. PLoS ONE 7(3): e34165. doi:10.1371/ journal.pone.0034165

Editor: Jianming Qiu, University of Kansas Medical Center, United States of America

Received December 7, 2011; Accepted February 23, 2012; Published March 30, 2012

Copyright: (c) 2012 Hu et al. This is an open-access article distributed under the terms of the Creative Commons Attribution License, which permits unrestricted use, distribution, and reproduction in any medium, provided the original author and source are credited.

Funding: This work was financially supported by the National High-tech Research and Development Program (863 Program) of China (No. 2007AA02Z108) http://www.863.gov.cn/, and the Chinese Science and Technology Key Projects (2012ZX10004503-011 and 2012ZX09103301-044) http://www.nmp.gov.cn/. The funders had no role in study design, data collection and analysis, decision to publish, or preparation of the manuscript.

Competing Interests: The authors have declared that no competing interests exist.

* E-mail: sqwang@nic.bmi.ac.cn (SW); jingyang0511@yahoo.com.cn (JY)

9 These authors contributed equally to this work.

\section{Introduction}

Structurally, microRNAs (miRNAs) are small noncoding RNAs with 18-25 nucleotides in length which are processed from short stem-loop precursors encoded by plant, animal and viral gemomes. The growing miRNA database (http://www.mirbase. org) currently contains $\sim 2100$ human miRNAs [1]. Bioinformatic analyses have suggested that miRNAs could regulate a number of genes and each mRNA could also be regulated by several miRNAs [2]. It is estimated that more than $30 \%$ of human genes are regulated by miRNAs [3]. miRNAs have been shown to play significant roles in a variety of physiological processes including organ development, cell differentiation, apoptosis and metabolism by either mediating translational arrest or degrading target transcripts [4-6].

Recent data has indicated that host miRNAs could be involved in host-virus interactions, and therefore could have a significant impact on the virus life-cycle [7]. Lecellier et al. [8] demonstrated for the first time that miR-32 possessed antiviral properties. Specifically, miR-32 was shown to inhibit primate foamy virus type 1 (PFV-1) mRNA translation and also restricted virus accumulation in cultured cells. In addition, miR-24 and miR-93 were found to target vesicular stomatitis virus (VSV) and protect mice against VSV infection [9]. In contrast, Jopling et al. reported that miR-122 was necessary for hepatitis $\mathrm{C}$ virus (HCV) replication by binding of miRNAs to the $5^{\prime}$ end of the viral genome [10]. HBV is a strict intracellular pathogen that infects primary hepatocytes and is the prototypic Hepadnaviridae family virus. HBV must utilize host cellular components and machinery as a means of completing replication and mediating pathogenesis. Therefore, we hypothesized whether hsa-miRNAs and HBV interactions could affect HBV replication.

This study screened a hsa-miRNA expression library and identified several miRNAs with the potential of interfering with HBV replication. Among the candidate miRNAs, miR-141 was further analysized by considering its good inhibition rate of $\mathrm{HBV}$ replication. Results presented in this report demonstrated that miRNA-141 inhibited HBV replication by reducing the transcriptional ability of HBV promoters by targeting the transcription factor peroxisome proliferator-activated receptor alpha (PPARA).

\section{Results}

Primary screening of HBV-replication related miRNAs

In order to identify miRNAs with the capacity of regulating HBV replication, 64 miRNAs functionally related to cell differentiation, viral infection and cancer were selected from a miRNA expression library. miRNA expression plasmids were cotransfected in triplicate into HepG2 cells with the pHBV1.3 plasmid. Cell culture supernatants were collected $48 \mathrm{~h}$ post transfection and screened for the presence of HBsAg by ELISA. Using this screening method, we identified miR-141, miR-125a and miR-125b could inhibit HBsAg expression in HepG2 cells, whereas miR-98 had the opposite effect (Fig. 1). Based on the 


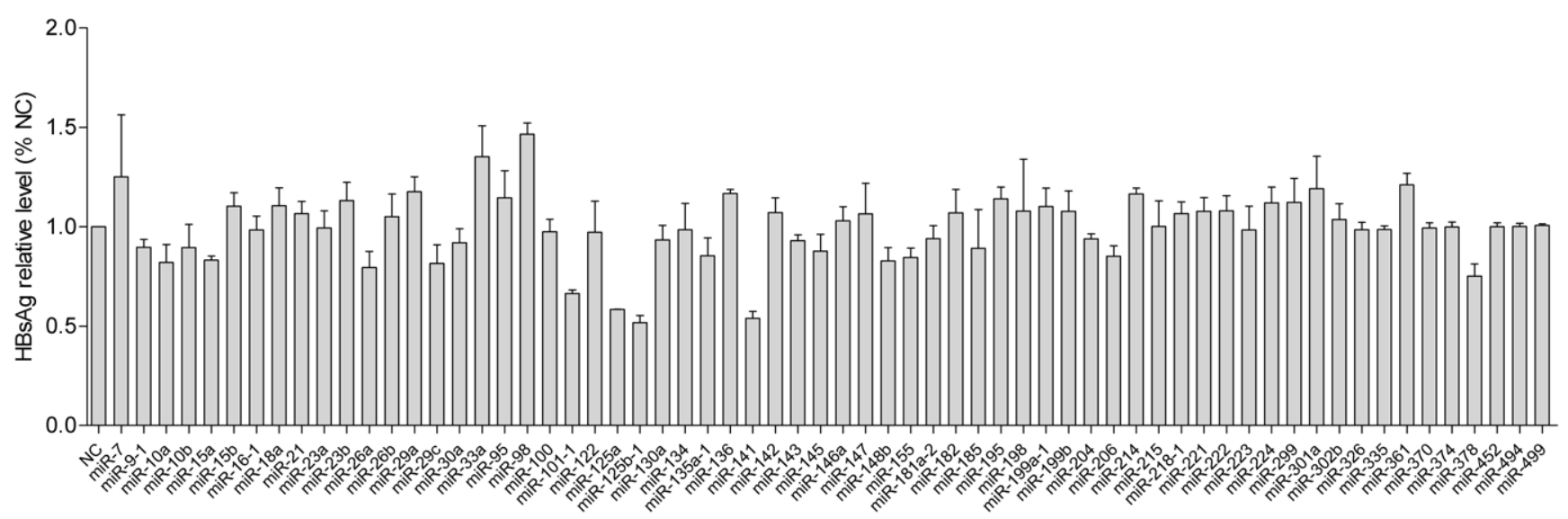

Figure 1. Screening for miRNAs involved in HBV expression. The negative control pcDNA3.0 plasmid and 64 miRNA expressing plasmids were co-transfected with the pHBV1.3 vector, respectively. The level of HBsAg in cell culture supernatants was detected by ELISA $48 \mathrm{~h}$ post transfection. The value in the negative control group was set at 1.0. doi:10.1371/journal.pone.0034165.g001

screening results and for the consideration of finding effective cellular anti-HBV miRNA, we subsequently selected miR-141 for the following HBV replication inhibition research.

\section{miR-141 mediated inhibition of HBV expression and replication}

miR-141 was further examined to confirm its ability to interfere with HBV replication by co-transfecting miR-141 mimics or miR141 inhibitor into HepG2 cells with pHBV1.3 plasmid. HBsAg/ $\mathrm{HBeAg}$ expression levels in cell culture supernatants were analyzed by ELISA and viral DNA isolated and analyzed by quantitative PCR (qPCR). These analyses confirmed that miR141 could repress HBV replication effectively, and that miR-141 inhibitor transfection resulted in a pronounced increase in $\mathrm{HBsAg} / \mathrm{HBeAg}$ expression had no significant effect on $\mathrm{HBV}$ DNA replication (Fig. 2). Both of these positive and negative activities indicated that miR-141 could repress HBV replication.

We next characterized the effect of miR-141 transfection related side-effects on host cells using the Cell Counting Kit-8 (CCK-8) and flow cytometry (FCM) to analyze cell viability and cell cycle progression, respectively. CGK-8 analysis showed that miR-141 mimics, as well as miR-141 inhibitor, had no significant effect on cell viability compared to negative control or mock treated cells (Fig. 3A, B). Flow cytometric analysis also showed that no significant differences in cell cycle progression could be observed between these experimental groups (Fig. 3C, D). These results validated the hypothesis that miR-141 could repress $\mathrm{HBV}$ replication without harming host cells.

\section{PPARA is a target of miR-141 in HBV-replication repression}

The results from the target gene prediction program TargetScan (www.targetscan.org) $[3,11,12]$ revealed that PPARA (a key liver-enriched transcription factor required for HBV pregenomic RNA synthesis and viral replication) might be a candidate miR141 gene target. Moreover, no putative target site for hsa-miR-141 was found in the HBV genome by the computational analysis. As shown in Fig. 4A, sequence analysis revealed that there were 4 candidate miR-141 binding sites in the PPARA mRNA $3^{\prime}$ untranslated region (UTRs) suggesting that PPARA was probably a miR-141 target gene.
The location of the first miR-141 binding site (binding site 1 ) is relatively distant from binding sites 2, 3 and 4 in the PPARA $3^{\prime}$ UTR. Binding site 1 and binding sites 2, 3 and 4 were cloned into the pGL3M vector separately as a means of identifying the miR141 binding site(s). The pGL3M-UTR vectors were then cotransfected with miR-141 mimics (or the negative control) into HEK293T cells. Luciferase assay results indicated that miR-141 significantly reduced the luciferase activity of the reporter plasmid containing binding sites 2, 3, and 4 but had no effect on the plasmid containing binding site 1 only (Fig. 4B). These results suggested that miR-141 targeted binding site 2,3 or 4 of the PPARA 3'-UTR. Subsequently, different deletants of PPARA 3'UTR containing only one of binding site 2, 3 or 4 were cloned into the pGL3M vector. Luciferase results indicated that miR-141 significantly reduced the luciferase activity of the 3 plasmids when 2 binding sites were deleted but had no effect on plasmid missing all the 3 binding sites (Fig. 4B). These results demonstrated that miR-141 regulated PPARA expression by targeting PPARA $3^{\prime}$ UTR binding sites 2, 3 and 4 (with no significant differences in their binding ability to miR-141).

To analyze interactions between miR-141 and PPARA in hepatocytes, miR-141 mimics was transfected into HepG2 cells and PPARA expression levels were detected by semi-quantitative RT-PCR and Western blot analyses. These results showed that miR-141 mimics markedly reduced both PPARA mRNA and protein levels compared to levels observed in the negative control miR-C transfected or mock treated cells (Fig. 4C, D). These results above indicated that miR-141 could regulate the expression of PPARA.

\section{Verification of PPARA function in HBV replication}

Although the importance of PPARA-RXR heterodimers in HBV replication has been reported previously [13-15], we confirmed these observations using our cell transfection model by silencing PPARA. HepG2 cells were transfected with PPARAspecific siRNAs only or with the pHBV1.3 plasmid. PPARA expression levels were determined by semi-quantitative RT-PCR and Western blot analyses and the $\mathrm{HBsAg} / \mathrm{HBeAg}$ levels in cell culture supernatants, as well as viral DNA loads within cells, were determined as described above. Results indicated that transfection of PPARA-specific siRNAs led to a significant decrease in PPARA levels (Fig. 5A, B) and that reductions in PPARA levels resulted in 
A

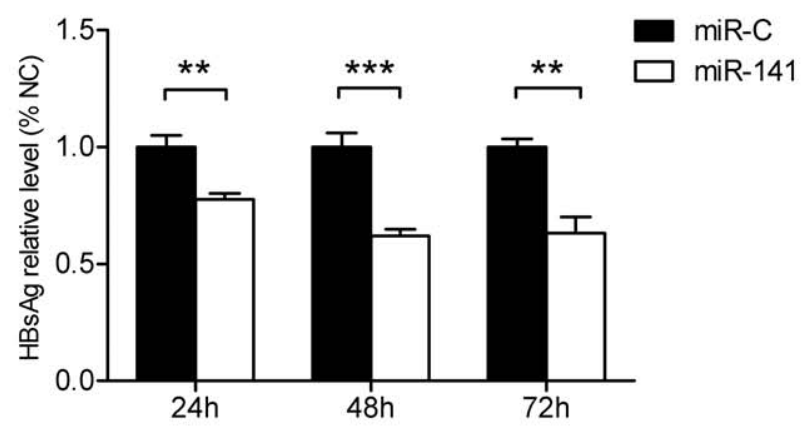

C

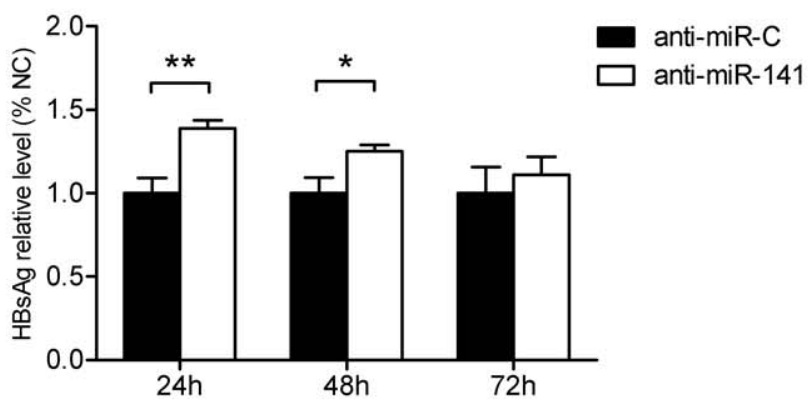

E

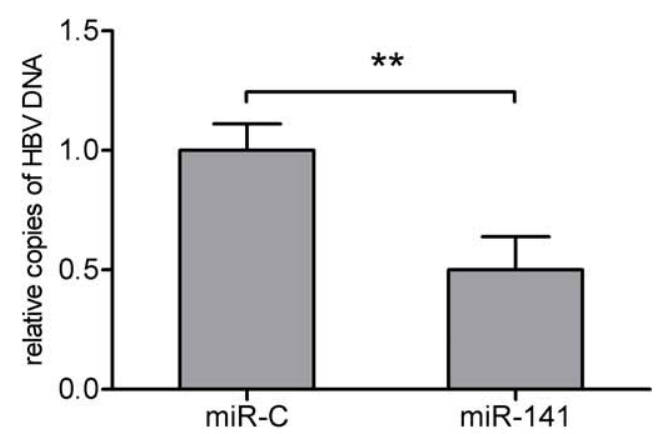

B

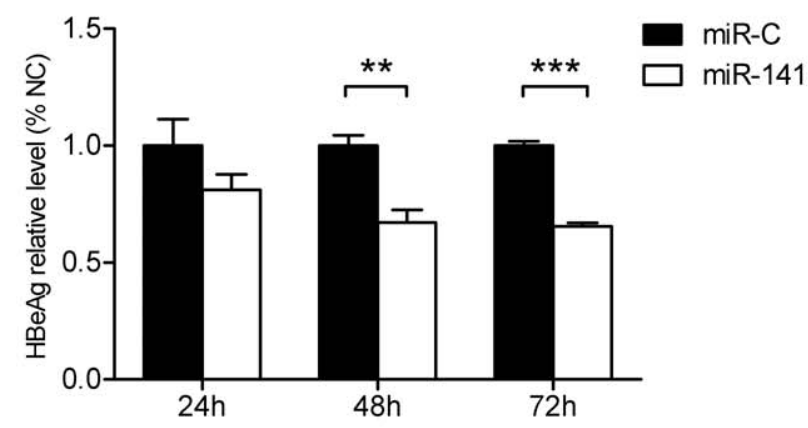

D

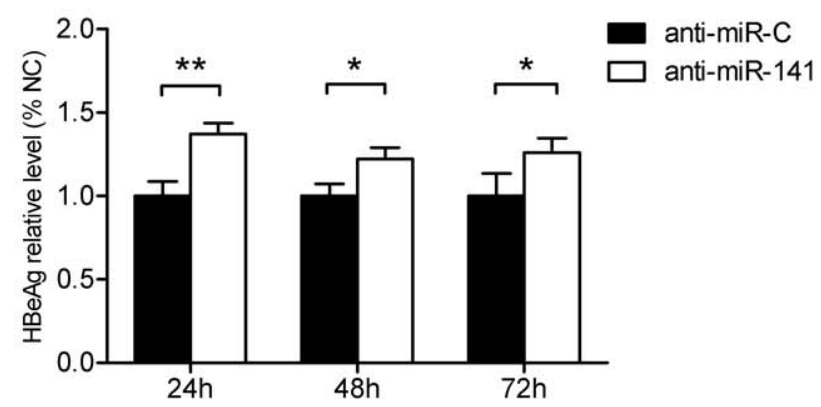

$\mathbf{F}$

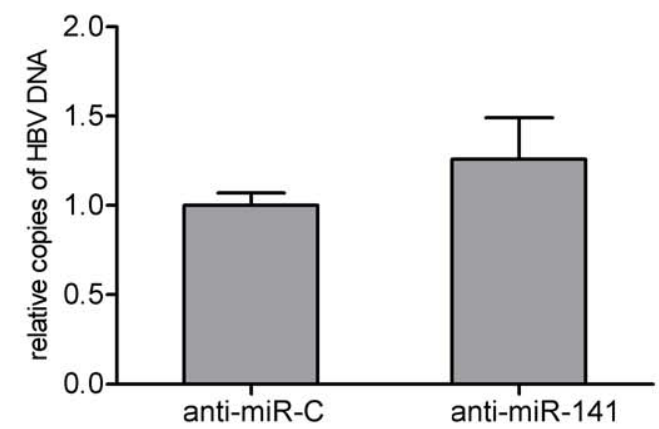

Figure 2. Effect of transfection with miR-141 mimics. Transfection of HepG2 cells with miR-141 mimics represses HBV expression and replication. By contrast, transfection with miR-141 inhibitor had the opposite effect. HepG2 cells were co-transfected with miR-141 mimics or miR-141 inhibitor together with the pHBV1.3 vector and analyzed for HBV protein expression. Oligonucleotides with scrambled sequences were used as negative controls (miR-C or anti-miR-C, respectively). HBsAg and HBeAg ELISA assays were used to screen culture supernatants 24,48 and $72 \mathrm{~h}$ after co-transfection with (A) miR-141 mimics and the pHBV1.3 vector or (B) miR-141 inhibitor and the pHBV1.3 vector. (C) qPCR detection of HBV DNA in HepG2 cells $72 \mathrm{~h}$ after co-transfection with the miR-141 mimics or miR-141 inhibitor together with pHBV1.3. The histograms show the relative HBsAg, $\mathrm{HBeAg}$ and HBV DNA levels compared to the negative control group. doi:10.1371/journal.pone.0034165.g002

a significant inhibition of $\mathrm{HBV}$ replication in HepG2 cells (Fig. 5C-E).

\section{miR-141 inhibits HBV replication by repressing HBV} promoters

Previous studies indicated that nuclear receptor PPARA activated HBV gene expression by interacting with $\mathrm{HBV}$ promoters [16-18]. We further verified the relationship between miR-141 and PPARA by carrying out promoter functional assays. The $4 \mathrm{HBV}$ promoter fragments (ENI/Xp, ENII/Cp, Spl, and Sp2) were cloned into the pGLuc-basic luciferase reporter vector, respectively, and then co-transfected into HepG2 cells in the presence of miR-141 mimics or PPARA-specific siRNAs.
Luminescence results demonstrated that miR-141 and siRNAs significantly reduced Gaussia luciferase expression compared to the negative control in the 4 promoter functional assays (Fig. 6).

\section{Discussion}

MicroRNAs are important small non-coding RNAs that primarily mediate post-transcriptional gene regulation. Increasing evidence suggests that there are complex interactions between cellular miRNAs and viral genes, suggesting that important regulatory networks exist between the virus, host miRNAs, and their respective target genes [8-10,19-21]. In this report, we studied the effects of cellular miRNAs on HBV replication and found that miR-141 possessed antiviral properties. 
A

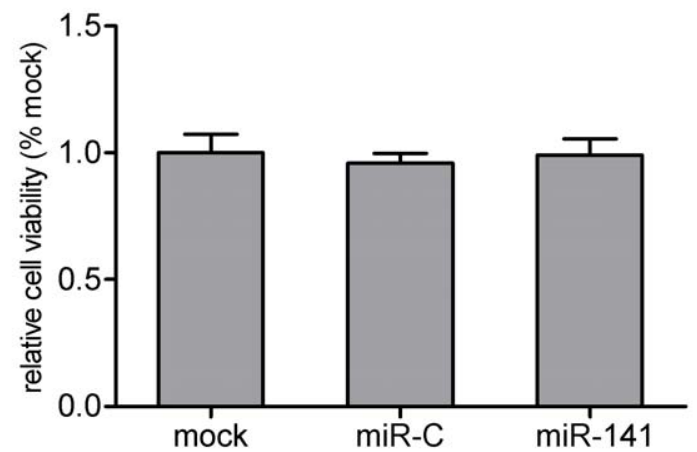

C
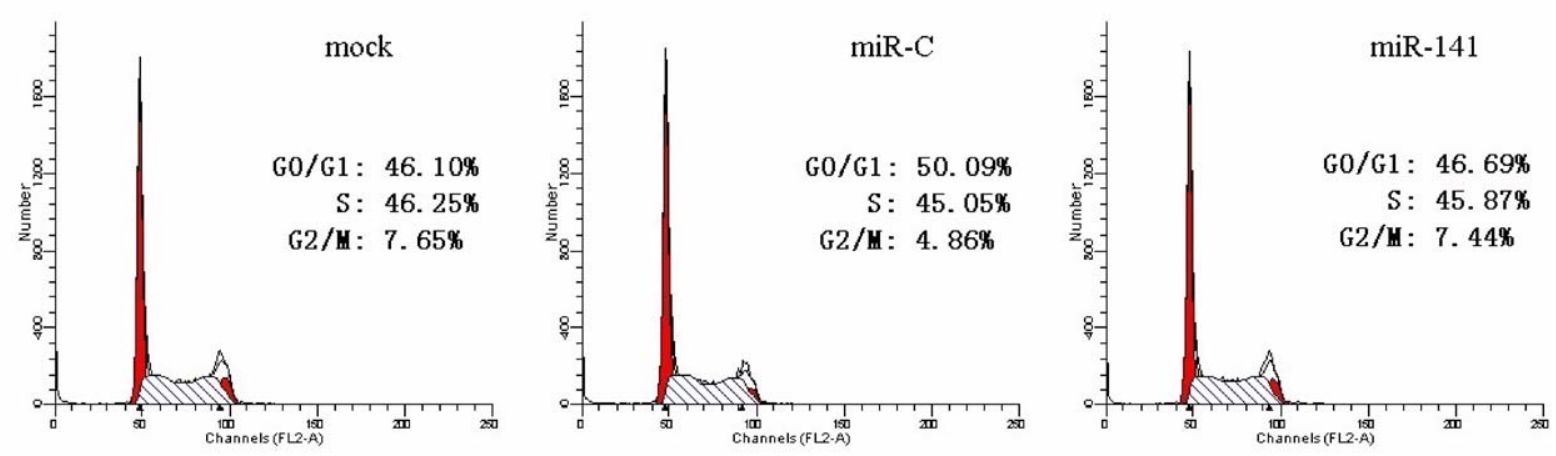

D

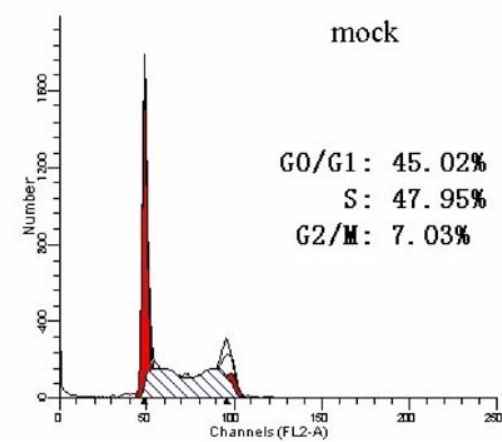

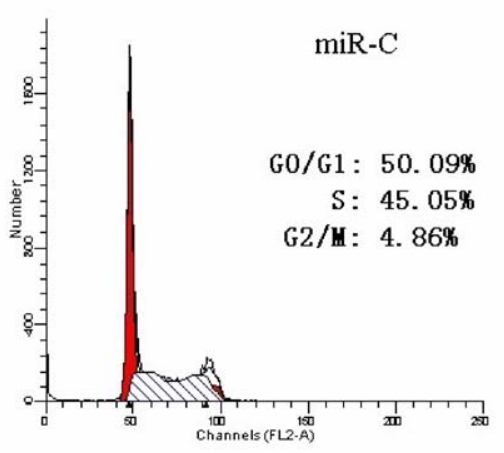

B

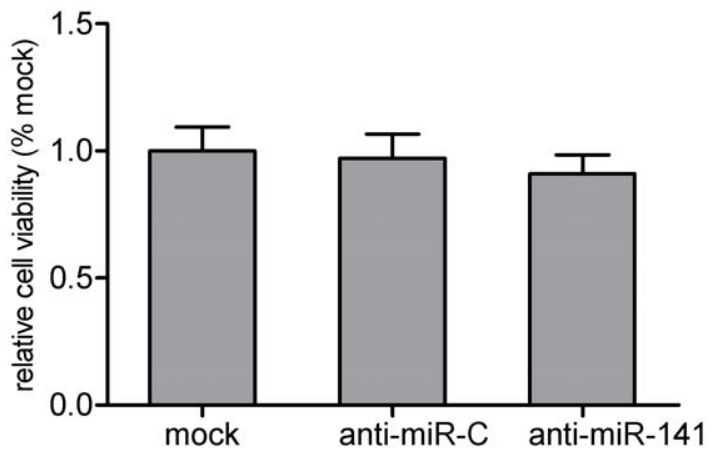

S: $45.87 \%$

G2/H: $7.44 \%$

anti-miR-141

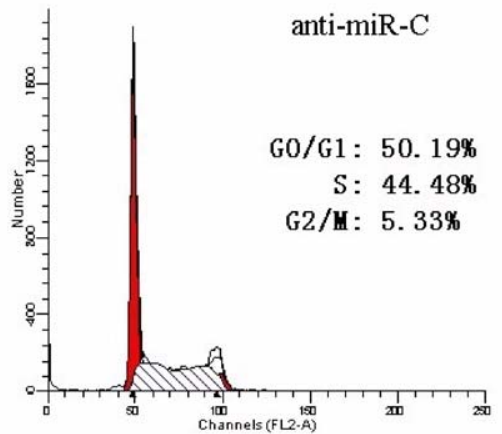

Figure 3. Transfection of miR-141 mimics or miR-141 inhibitor has no significant influence on HepG2 cell viability or cell cycle progression. HepG2 cells were transfected with miR-141 mimics or miR-141 inhibitor only and analyzed $72 \mathrm{~h}$ post transfection. Scrambled oligonucleotides were used as negative controls (miR-C or anti-miR-C, respectively). (A) HepG2 cell viability was measured using the CCK-8 assay. Data are expressed as fold change relative to mock treated cells. (B) HepG2 cell cycle analysis was performed by flow cytometry. Percent cells in each phase of the cell cycle are shown.

doi:10.1371/journal.pone.0034165.g003

Recent data suggested that the cellular miRNAs could regulate HBV propagation directly or indirectly by targeting cellular factors. Potenza et al. demonstrated that hsa-miR-125a-5p interacted with HBV sequences and repressed HBsAg expression [22]. Our primary screening of HBV replication-related miRNAs showed similar results, indicating that a pri-miR-125a expression vector could repress HBsAg synthesis in HepG2 cells. Although miR-125a-5p was shown to repress HBsAg expression by targeting HBV sequences directly, interactions between host cell proteins and miR-125a-5p could not be excluded. On the other hand, Lu et al. recently demonstrated that miR-1 enhanced HBV core promoter activity by increasing the expression levels of the farnesoid X receptor alpha (FXRA), an essential HBV cellular transcription factor [23]. In the present study, exogenous expression of miR-141 could significantly inhibit HBV expression and DNA replication, whereas miR-141 inhibitor transfection had the opposite effects on $\mathrm{HBsAg} / \mathrm{HBeAg}$ expression. Though the regulation of HBV replication by miR-141 inhibitor is less effective than miR-141 mimics, it is possible due to the relative low expression level of miR-141 in HepG2 cells (Information S1). These data suggest that miR-141 could suppress HBV transcription and replication.

HBV contains a $3.2 \mathrm{~kb}$ partially double-stranded DNA genome with four promoters (the core, pre-S1, pre-S2/S, and X promoters) and two enhancer regions (ENI and ENII) involved in viral transcription regulation $[24,25]$, and transcriptional regulation 
A

\begin{tabular}{|c|c|c|}
\hline Targetscan 5.2 & $\begin{array}{l}\text { predicted consequential pairing of target region } \\
\text { (top) and miRNA (bottom) }\end{array}$ & $\begin{array}{l}\text { Seed } \\
\text { match }\end{array}$ \\
\hline $\begin{array}{c}\text { Binding site } 1 \text { of PPARA } 3^{\prime} \\
\text { UTR } \\
\text { hsa-miR-141 }\end{array}$ & 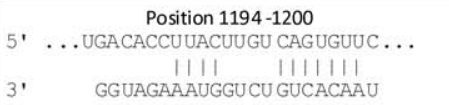 & 7 mer-m 8 \\
\hline $\begin{array}{c}\text { Binding site } 2 \text { of PPARA } 3^{\prime} \\
\text { UTR } \\
\text { hsa-miR-141 }\end{array}$ & 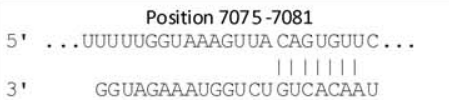 & 7 mer-m 8 \\
\hline $\begin{array}{c}\text { Binding site } 3 \text { of PPARA } 3^{\prime} \\
\text { UTR } \\
\text { hsa-miR-141 }\end{array}$ & 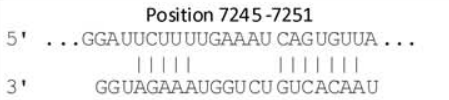 & $8 \mathrm{mer}$ \\
\hline $\begin{array}{c}\text { Binding site } 4 \text { of PPARA } 3^{\prime} \\
\text { UTR } \\
\text { hsa-miR-141 }\end{array}$ & 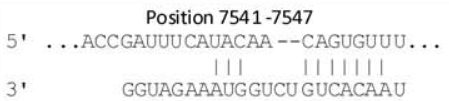 & $7 m e r-m 8$ \\
\hline
\end{tabular}

C

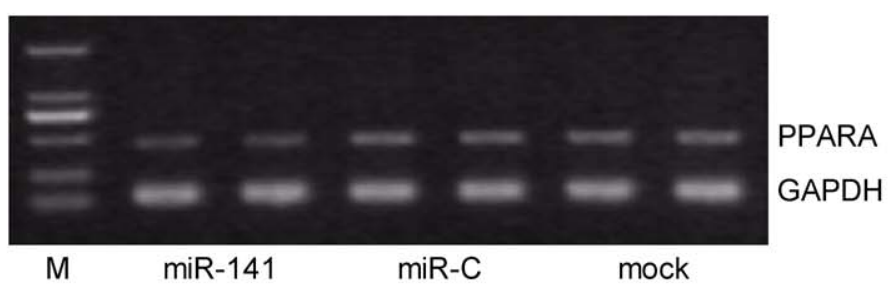

M

miR-141

mock
B
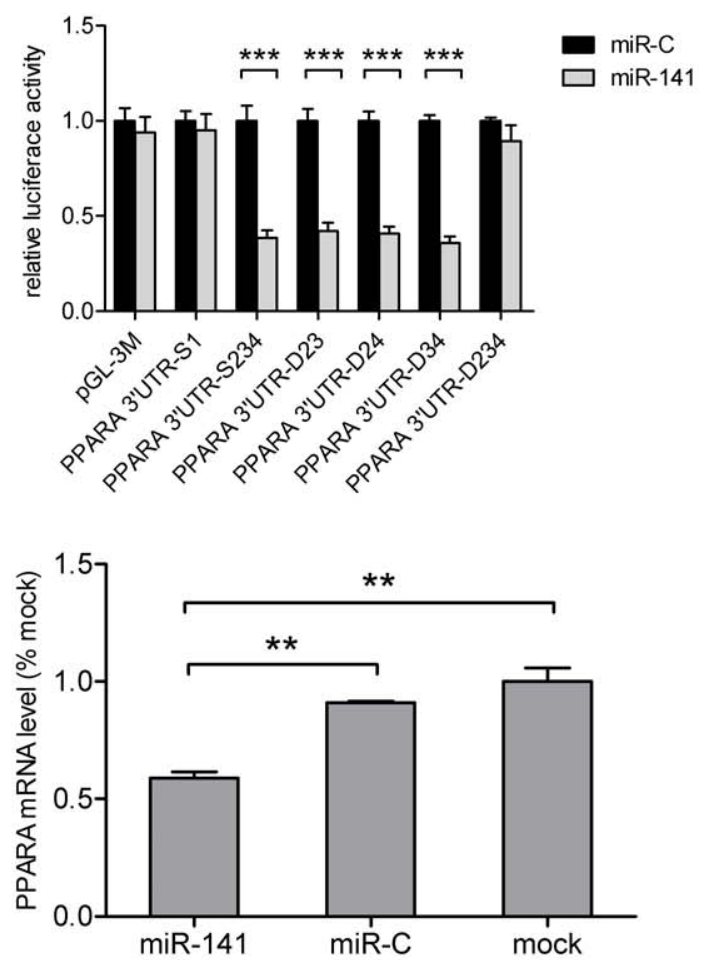

D

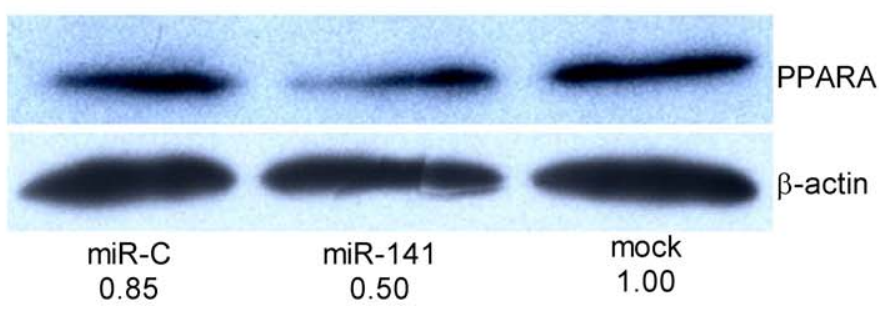

Figure 4. PPARA is the target of miR-141. (A) Four possible miR-141 target sites on the PPARA $3^{\prime}$-UTR were predicted by TargetScan software. (B) Putative miR-141 target sites 2, 3, and 4 in the PPARA 3'-UTR were functional in a dual-luciferase reporter assay. miR-141 mimics or a miRNA control were co-transfected with the luciferase reporter vector containing wild-type binding site 1 or binding sites 2 , 3, and 4 of the PPARA $3^{\prime}$-UTR or different PPARA 3'-UTR deletion constructs containing only one binding site, respectively. Luciferase activity was determined $48 \mathrm{~h}$ after transfection. The histogram shows the normalized Firefly/Renilla luciferase activities as relative values compared to the miR-C negative control. Regulation mediated by miR-141 mimics on PPARA mRNA and protein expression were analyzed, respectively, by (C) semi-quantitative RT-PCR or (D) Western blot. GAPDH and $\beta$-actin were used as internal controls, respectively. The ratio of the PPARA to GAPDH or $\beta$-actin band intensities are shown. The value of mock transfected cells was set at 1.0. (Lane $\mathrm{M}$, molecular weight standards).

doi:10.1371/journal.pone.0034165.g004

plays a central role in control of HBV replication [26]. HBV promoter and enhancer activities are regulated by a number of transcription factors [27]. For example, the core promoter, pre-S1 promoter, $\mathrm{X}$ promoter, ENI and ENII all contain a PPARA binding site and these regions were found to be transactivated in the presence of RXRA and PPARA [17]. Tang and McLachlan also demonstrated that nuclear hormone receptors (NRs), including HNF4, RXRA and PPARA, were essential liverenriched transcription factors associated with $\mathrm{HBV}$ pregenomic RNA synthesis and viral replication in nonhepatic cell lines [14]. Since pregenomic RNA encodes both polymerase and core protein (and serves as the template for viral DNA synthesis), it is likely that PPARA plays a critical role in HBV biogenesis.

The peroxisome proliferator-activated receptors (PPARs) that consist of PPAR $\alpha, \operatorname{PPAR} \beta$, and $\operatorname{PPAR} \gamma$ are ligand-activated transcription factors that belong to the nuclear hormone receptor superfamily $[28,29]$. PPARs serve as lipid metabolism regulators and influence cellular proliferation, differentiation and apoptosis [30,31]. The luciferase reporter assay showed that miR-141 suppressed reporter activity significantly via 3 binding sites in the PPARA 3'-UTR. PPARA mRNA and protein levels were both reduced by miR-141 mimics transfection. This suggested that miR-141 would be an effective regulator of HBV replication by interfering with PPARA expression. Furthermore, our results showed that PPARA knockdown by miR-141 mimics or siRNA exerted a negative effect on HBV replication and reduced the HBV promoter transcription activities. This was consistent with previous findings regarding PPARA functional activity, suggesting that inhibition of HBV replication by miRNA-141 was mainly mediated via PPARA repression. Therefore, overexpression of miR-141 may be an effective strategy for diminishing HBV replication. 


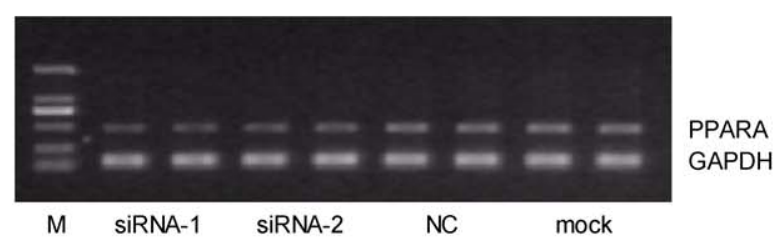

B

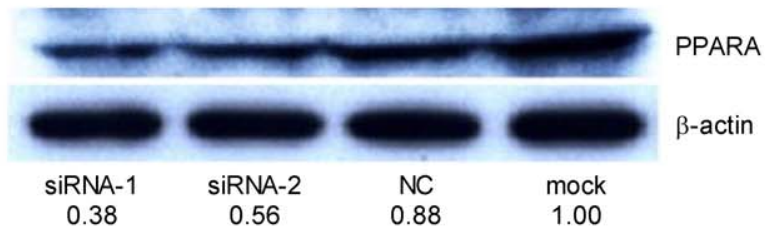

D

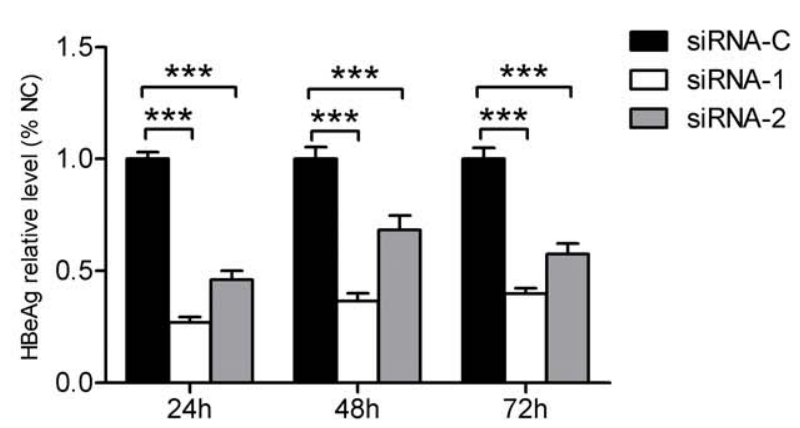

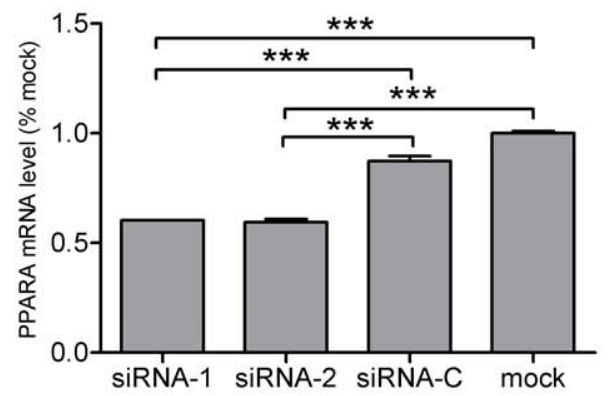

C

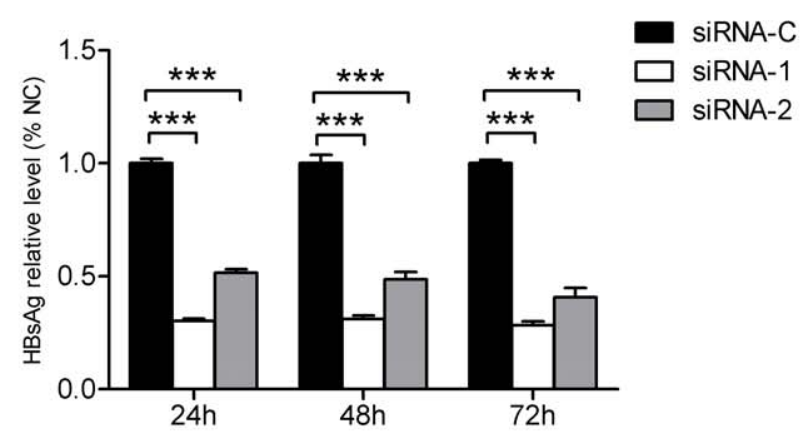

$\mathbf{E}$

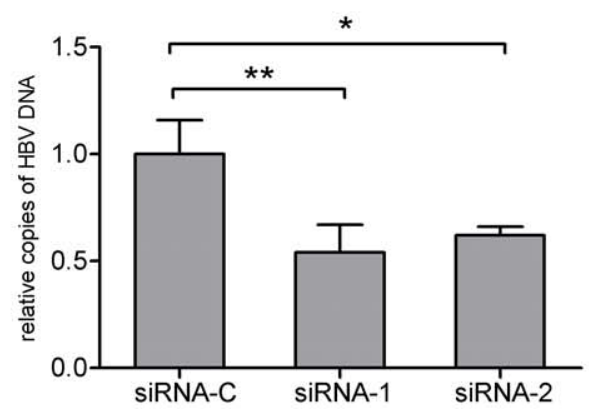

Figure 5. Silencing of PPARA by siRNA represses HBV replication in HepG2 cells. The levels of PPARA mRNA and protein in HepG2 cells $48 \mathrm{~h}$ post transfection with PPARA specific siRNA were analyzed, respectively, by (A) semi-quantitative RT-PCR or (B) Western blot. GAPDH and $\beta$-actin were used as internal controls, respectively. The ratio of the band intensities were determined as described above (Lane $M$, molecular weight standards). The levels of (C) HBsAg and (D) HBeAg were determined 24, 48 and $72 \mathrm{~h}$ post transfection. (E) HBV DNA concentrations were determined $72 \mathrm{~h}$ post transfection. Relative levels were normalized as a percentage of the negative control siRNA-C.

doi:10.1371/journal.pone.0034165.g005

In conclusion, our data suggested that miR-141 down regulated HBV expression and replication by targeting cellular nuclear factor PPARA, and that PPARA could be a promising hostoriented drug target for the development of novel HBV therapy. Considering the importance and complexity of miRNAs in virushost regulatory networks, further systematic studies will be necessary to fully unravel the role of miRNAs in viral replication. This would not only increase our knowledge regarding HBV pathogenesis mechanisms but also help in the development of novel antiviral therapeutic approaches.

\section{Materials and Methods}

\section{Reagents}

hsa-miR-141 2'-O-methyl (2'-OMe) mimic oligonucleotides, hsa-miR-141 inhibitor, PPARA-specific siRNAs and unrelated sequence negative controls were purchased from Genepharma
(Shanghai, China). Sense and antisense PPARA siRNAs sequences were: siRNA-1, 5'-CGAAUGGCAUCGAGAACAA dTdT and 5'-UUGUUGUGGAUGGCAUUGG dTdT; siRNA-2, 5'GCAAUGGACCAUGUAACAA dTdT and 5'-UUGUUACAUGGUCGAUUGC dTdT, respectively. DNA oligonucleotides were synthesized by Sangon Biotech (Shanghai, China). An expression library of 64 miRNAs was obtain from Xiaofei Zheng (Beijing Institute of Radiation Medicine) as described previously [32]. The HBV replication-competent vector $\mathrm{pHBV} 1.3$ containing 1.3 copies of the HBV genome (ayw subtype, GenBank accession number: V01460) was provided by Dr. Hua Tang (Chongqing Medical University, Chongqing, China).

\section{Cell culture and transfection}

HepG2 and HEK293T cells (obtained from the American Type Culture Collection, Manassas, VA) were cultured in Dulbecco's Modified Eagle Medium (DMEM, GIBCO) containing 10\% fetal 


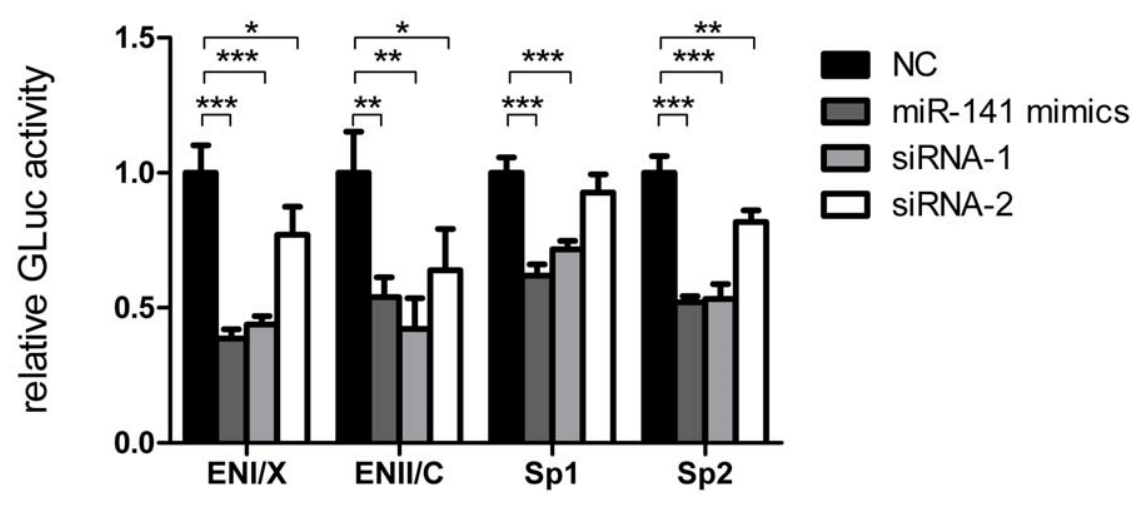

Figure 6. The influence of miR-141 on the activity of HBV ENI/Xp, ENII/Cp, Sp1 and Sp2 promoters. Gaussia and Renilla luciferase activities were determined $48 \mathrm{~h}$ post transfection. The data normalized to Renilla luciferase activity were expressed as the percentage of the negative control. miR-141 mimics and siRNA used the same oligonucleotide for the negative control.

doi:10.1371/journal.pone.0034165.g006

bovine serum (FBS, Hyclone), $100 \mathrm{U} / \mathrm{ml}$ penicillin and $100 \mu \mathrm{g} / \mathrm{ml}$ streptomycin and maintained at $37^{\circ} \mathrm{C}$ in a humidified $5 \% \mathrm{CO}_{2}$ atmosphere. Plasmids, miRNAs and siRNAs were co-transfected into cells at the indicated concentrations using Lipofectamine 2000 (Invitrogen, Carlsbad, CA) following the manufacturer's protocol $24 \mathrm{~h}$ after plating.

\section{HBV replication analysis}

Cell culture media was changed and collected at 24, 48 and $72 \mathrm{~h}$ post transfection and centrifugated at $500 \times \mathrm{g}$ for $5 \mathrm{~min}$ to remove debris before analysis. Supernatant $\mathrm{HBsAg}$ and $\mathrm{HBeAg}$ levels were determined using ELISA kits (Kehua Biotech, Shanghai, China). HBV DNA from intracellular core particles was extracted at $72 \mathrm{~h}$ post transfection as described previously [33]. Cells were lysed with $0.2 \mathrm{ml} 0.5 \%$ Nonidet P-40 in $50 \mathrm{mM}$ Tris-HCl and $1 \mathrm{mM}$ EDTA ( $\mathrm{pH}$ 8.0) for $10 \mathrm{~min}$. Lysates were centrifuged at $1,000 \times \mathrm{g}$ for $1 \mathrm{~min}$ to remove nuclei and the supernatants centrifuged for an additional $5 \mathrm{~min}$ at $14,000 \times \mathrm{g}$ to clear cellular debris. Supernatants were then readjusted to $5 \mathrm{mM} \mathrm{CaCl} 2$ and digested with 800 units $/ \mathrm{ml}$ micrococcal nuclease (New England Biolabs, Ipswich, MA) for $2 \mathrm{~h}$ at $37^{\circ} \mathrm{C}$ to eliminate residual plasmid DNA and unencapsidated HBV RNA. After nuclease inactivation using EDTA $(10 \mathrm{mM})$, viral DNA was extracted using the Column Viral DNAout kit (TIANDZ, China) following the manufacturer's protocol and quantified by real-time PCR as described previously [34].

\section{Western blot analysis}

Total HepG2 cellular proteins were prepared in RIPA buffer (50 mM Tris-HCl, pH 7.4, 150 mM NaCl, 0.1\% SDS, 1\% NP-40) containing a protease inhibitor cocktail (Roche Molecular Biochemicals, Mannheim, Germany). Polyacrylamide gel electrophoresis (PAGE) and protein transfer to Hybond polyvinylidene difluoride membranes (Amersham, Arlington Heights, IL, USA) were carried out following standard protocols. Monoclonal antibody against PPARA (sc-130640, Santa Cruz, USA) and $\beta$ actin (sc-1616-R, Santa Cruz) were used for immunodetection according to the manufacturer's instructions. Protein bands were visualized by autoradiogram using ECL Plus Western blot detection reagents (GE Healthcare Life Sciences) and quantified using Gel Pro Analyzer software v4.0 (Media Cybernetics, Bethesda, MD).

\section{RNA extraction and semi-quantitative RT-PCR}

Total RNA was extracted using TRIzol Reagent (Invitrogen) as recommended by the manufacturer. Semi-quantitative RT-PCR using a 2-step method was used to determine PPARA mRNA expression levels. Reverse transcription was performed following the SuperScript ${ }^{\mathrm{TM}}$ III Reverse Transcriptase (Invitrogen) protocol. PCR was performed for PPARA amplification using the following conditions: $94^{\circ} \mathrm{C}$ for $4 \mathrm{~min}$ followed by 29 cycles at $94^{\circ} \mathrm{C}$ for $20 \mathrm{~s}, 55^{\circ} \mathrm{C}$ for $20 \mathrm{~s}$, and $72^{\circ} \mathrm{C}$ for $40 \mathrm{~s}$ with a final extension at $72^{\circ} \mathrm{C}$ for $5 \mathrm{~min}$ and for GAPDH amplification using the following conditions: $94^{\circ} \mathrm{C}$ for 4 min followed by 27 cycles at $94^{\circ} \mathrm{C}$ for $20 \mathrm{~s}$, $55^{\circ} \mathrm{C}$ for $20 \mathrm{~s}$, and $72^{\circ} \mathrm{C}$ for $40 \mathrm{~s}$ with the final extension at $72^{\circ} \mathrm{C}$ for $5 \mathrm{~min}$. DNA products were analyzed by $1.0 \%$ agarose gel electrophoresis and visualized following ethidium bromide staining under UV light and band intensities measured by scanning with Gel Doc 1000 (Bio-Rad, Hercules, CA). The products were quantified by densitometry, and GAPDH mRNA levels used for normalization. The primers used for PPARA and GAPDH amplification were: PPARA-F, 5'-CGTCTCAGGAAAGGGCAGTA-3', PPARA-R, 5'-TCGACAGCAAATGATAGCAG3', GAPDH-F, 5'-GTCAAGCTCATTTCGTGGTATG-3' and GAPDH-R, 5'-CTTCGTCTTGTGCTCTTGCTG-3' .

\section{Luciferase reporter assays}

During the miRNA-target validation test, the 3'-UTRs containing the miR-141 predicted target sites were amplified by PCR from HepG2 cell genomic DNA and cloned into a modified pGL3control plasmid (pGL3M) as described previously [32]. HEK293T cells were co-transfected with $200 \mathrm{ng}$ of pGL3M-UTR constructs and 10 pmol miRNA mimics or a negative control per well in 24well plates using the Lipofectamine ${ }^{\mathrm{TM}} 2000$ transfection reagent. pRL-CMV (Promega, Madison, WI) was co-transfected as a normalization control. Luciferase activity assays were performed $48 \mathrm{~h}$ post transfection using the Dual-Luciferase Reporter Assay System (Promega).

During promoter functional analysis using dual-luciferase promoter assays, PCR fragments containing $\mathrm{HBV}$ promoters (ENI/Xp, nt 957-1354; ENII/Cp, nt 1627-1878; Sp1, nt 2704 2823; Sp2, nt 2978-3207) [35] were cloned into the pGLuc-Basic vector (New England Biolabs) upstream of the secretory Gaussia princeps luciferase, respectively. HepG2 cells were co-transfected with $500 \mathrm{ng}$ of pGLuc-promoter constructs and 20 pmol miRNA mimics or PPARA specific siRNAs per well in 24-well plates using Lipofectamine $^{\mathrm{TM}} 2000$ transfection reagent with pRL-CMV as a normalization control. Dual-luciferase assays were carried out $48 \mathrm{~h}$ post transfection according to the manufacturer's protocol (New England Biolabs). 


\section{Cell viability and cell cycle analysis}

HepG2 cells were transfected with miR-141 mimics or miR-141 inhibitor only. Cell viability was determined using the Cell Counting Kit-8 kit (Dojindo, Kumamoto, Japan) $72 \mathrm{~h}$ after transfection. For cell cycle analysis, cells were harvested, combined, washed once in phosphate-buffered saline (PBS), and then fixed in $70 \%$ ethanol overnight $72 \mathrm{~h}$ after transfection. Staining for DNA content was performed with $50 \mu \mathrm{g} / \mathrm{ml}$ propidium iodide and $1 \mathrm{mg} / \mathrm{ml}$ RNase $\mathrm{A}$ at $37^{\circ} \mathrm{C}$ for $30 \mathrm{~min}$. Stained cells were analyzed for cell cycle distribution on a FACScalibur flow cytometer (Becton Dickinson, USA).

\section{Statistical analysis}

The data presented are expressed as mean \pm standard deviation (SD) and statistical significance was determined by the Student's $t$ test or one-way ANOVA. $P$-values are indicated by asterisks $(* * * P<0.001, * * P<0.01, * P<0.05)$.

\section{Supporting Information}

Information $S 1$ The expression level of miR-141 was relative low in HepG2 cells. Total RNA was extracted from the cultured cells using Trizol Reagent (Invitrogen) and the

\section{References}

1. Kozomara A, Griffiths-Jones S (2011) miRBase: integrating microRNA annotation and deep-sequencing data. Nucleic Acids Res 39: D152-157.

2. Brodersen P, Voinnet $\mathrm{O}$ (2009) Revisiting the principles of microRNA target recognition and mode of action. Nat Rev Mol Cell Biol 10: 141-148.

3. Lewis BP, Burge CB, Bartel DP (2005) Conserved seed pairing, often flanked by adenosines, indicates that thousands of human genes are microRNA targets. Cell 120: $15-20$

4. Bartel DP (2004) MicroRNAs: genomics, biogenesis, mechanism, and function. Cell 116: 281-297.

5. Stefani G, Slack FJ (2008) Small non-coding RNAs in animal development. Nat Rev Mol Cell Biol 9: 219-230.

6. Kumar MS, Lu J, Mercer KL, Golub TR, Jacks T (2007) Impaired microRNA processing enhances cellular transformation and tumorigenesis. Nat Genet 39: 673-677.

7. Umbach JL, Cullen BR (2009) The role of RNAi and microRNAs in animal virus replication and antiviral immunity. Genes Dev 23: 1151-1164.

8. Lecellier CH, Dunoyer P, Arar K, Lehmann-Che J, Eyquem S, et al. (2005) A cellular microRNA mediates antiviral defense in human cells. Science 308: $557-560$.

9. Otsuka M, Jing Q Georgel P, New L, Chen J, et al. (2007) Hypersusceptibility to vesicular stomatitis virus infection in Dicer1-deficient mice is due to impaired miR24 and miR93 expression. Immunity 27: 123-134.

10. Jopling CL, Yi M, Lancaster AM, Lemon SM, Sarnow P (2005) Modulation of hepatitis C virus RNA abundance by a liver-specific MicroRNA. Science 309: 1577-1581.

11. Grimson A, Farh KK, Johnston WK, Garrett-Engele P, Lim LP, et al. (2007) MicroRNA targeting specificity in mammals: determinants beyond seed pairing. Mol Cell 27: 91-105.

12. Friedman RC, Farh KK, Burge CB, Bartel DP (2009) Most mammalian mRNAs are conserved targets of microRNAs. Genome Res 19: 92-105.

13. Guidotti LG, Eggers CM, Raney AK, Chi SY, Peters JM, et al. (1999) In vivo regulation of hepatitis $\mathrm{B}$ virus replication by peroxisome proliferators. J Virol 73: 10377-10386.

14. Tang H, McLachlan A (2001) Transcriptional regulation of hepatitis B virus by nuclear hormone receptors is a critical determinant of viral tropism. Proc Natl Acad Sci U S A 98: 1841-1846.

15. Tseng YP, Kuo YH, Hu CP, Jeng KS, Janmanchi D, et al. (2008) The role of helioxanthin in inhibiting human hepatitis $\mathrm{B}$ viral replication and gene expression by interfering with the host transcriptional machinery of viral promoters. Antiviral Res 77: 206-214.

16. Huan B, Kosovsky MJ, Siddiqui A (1995) Retinoid X receptor alpha transactivates the hepatitis $\mathrm{B}$ virus enhancer 1 element by forming a heterodimeric complex with the peroxisome proliferator-activated receptor. J Virol 69: 547-551.

17. Raney AK, Johnson JL, Palmer CN, McLachlan A (1997) Members of the nuclear receptor superfamily regulate transcription from the hepatitis B virus nucleocapsid promoter. J Virol 71: 1058-1071. expression levels of small RNAs were confirmed by quantitative RT-PCR using miRNA Real-Time PCR Assay kit (CW Biotech, China) according to the manufacturer's protocol. The expression level of miR-141 was relative low compared with miR-24 which is expressed constitutively in HepG2 cells. The forward primer of RNAs amplification was RNA specific as shown in the table, and the reverse primer was a universal primer containing in the kit. The U6 snRNA expression level was used for normalization.

(XLS)

\section{Acknowledgments}

The authors would like to thank Prof. Xiaofei Zheng (Beijing Institute of Radiation Medicine) for the miRNA expression library and Dr. Hua Tang (Chongqing Medical University, Chongqing, People's Republic of China) for the pHBV1.3 plasmid.

\section{Author Contributions}

Conceived and designed the experiments: XW SW. Performed the experiments: WH XW XD YL. Analyzed the data: WH XW JY SW. Contributed reagents/materials/analysis tools: XZ PX. Wrote the paper: WH XW SW.

18. Yu X, Mertz JE (2001) Critical roles of nuclear receptor response elements in replication of hepatitis B virus. J Virol 75: 11354-11364.

19. Sung TL, Rice AP (2009) miR-198 inhibits HIV-1 gene expression and replication in monocytes and its mechanism of action appears to involve repression of cyclin T1. PLoS Pathog 5: e1000263.

20. Qiu L, Fan H, Jin W, Zhao B, Wang Y, et al. (2010) miR-122-induced downregulation of HO-1 negatively affects miR-122-mediated suppression of $\mathrm{HBV}$. Biochem Biophys Res Commun 398: 771-777.

21. Zheng SQ, Li YX, Zhang Y, Li X, Tang H (2011) MiR-101 regulates HSV-1 replication by targeting ATP5B. Antiviral Res 89: 219-226.

22. Potenza N, Papa U, Mosca N, Zerbini F, Nobile V, et al. (2011) Human microRNA hsa-miR-125a-5p interferes with expression of hepatitis $\mathrm{B}$ virus surface antigen. Nucleic Acids Res 39: 5157-5163.

23. Zhang X, Zhang E, Ma Z, Pei R, Jiang M, et al. (2011) Modulation of hepatitis $\mathrm{B}$ virus replication and hepatocyte differentiation by MicroRNA-1. Hepatology 53: $1476-1485$.

24. Ganem D, Varmus HE (1987) The molecular biology of the hepatitis B viruses. Annu Rev Biochem 56: 651-693.

25. Seeger C, Mason WS (2000) Hepatitis B virus biology. Microbiol Mol Biol Rev 64: 51-68.

26. Tang H, Banks KE, Anderson AL, McLachlan A (2001) Hepatitis B virus transcription and replication. Drug News Perspect 14: 325-334.

27. Quasdorff M, Protzer U (2010) Control of hepatitis B virus at the level of transcription. J Viral Hepat 17: 527-536.

28. Kersten S, Desvergne B, Wahli W (2000) Roles of PPARs in health and disease. Nature 405: 421-424.

29. Chawla A, Repa JJ, Evans RM, Mangelsdorf DJ (2001) Nuclear receptors and lipid physiology: opening the X-files. Science 294: 1866-1870.

30. Berger J, Moller DE (2002) The mechanisms of action of PPARs. Annu Rev Med 53: 409-435.

31. Michalik L, Auwerx J, Berger JP, Chatterjee VK, Glass CK, et al. (2006) International Union of Pharmacology. LXI. Peroxisome proliferator-activated receptors. Pharmacol Rev 58: 726-741.

32. Cui J, Fu H, Feng J, Zhu J, Tie Y, et al. (2007) The construction of miRNA expression library for human. ProgBiochem Biophys 34: 389-394.

33. Lewellyn EB, Loeb DD (2007) Base pairing between cis-acting sequences contributes to template switching during plus-strand DNA synthesis in human hepatitis B virus. J Virol 81: 6207-6215.

34. He Y, Wang S, Chen S, Chen Z, Wang X, et al. (2001) Construction and clinical application of a new fluorescent quantitative polymerase chain reaction technique for HBV detection. Chin J Hepatol 9: 376-377.

35. Qin J, Zhai J, Hong R, Shan S, Kong Y, et al. (2009) Prospero-related homeobox protein (Proxl) inhibits hepatitis B virus replication through repressing multiple cis regulatory elements. J Gen Virol 90: 1246-1255. 